\title{
BMJ Open Cohort profile: the COVID-19 Coping Study, a longitudinal mixed-methods study of middle-aged and older adults' mental health and well-being during the COVID-19 pandemic in the USA
}

To cite: Kobayashi LC, 0'Shea BQ, Kler JS, et al. Cohort profile: the COVID-19 Coping Study, a longitudinal mixed-methods study of middle-aged and older adults' mental health and well-being during the COVID-19 pandemic in the USA. BMJ Open 2021;11:e044965. doi:10.1136/ bmjopen-2020-044965

- Prepublication history and additional materials for this paper is available online. To view these files, please visit the journal online (http://dx.doi. org/10.1136/bmjopen-2020044965).

Received 17 September 2020 Revised 07 December 2020 Accepted 25 January 2021

Check for updates

(C) Author(s) (or their employer(s)) 2021. Re-use permitted under CC BY-NC. No commercial re-use. See rights and permissions. Published by BMJ.

For numbered affiliations see end of article.

Correspondence to Dr Lindsay C Kobayashi; Ikob@umich.edu

\section{ABSTRACT}

Purpose The COVID-19 pandemic, beginning in early 2020, has resulted in massive social, economic, political and public health upheaval around the world. We established a national longitudinal cohort study, the COVID-19 Coping Study, to investigate the effects of pandemic-related stressors and changes in life circumstances on mental health and well-being among middle-aged and older adults in the USA.

Participants From 2 April to 31 May 2020, 6938 adults aged $\geq 55$ years were recruited from all 50 US states, the District of Columbia and Puerto Rico using online, multiframe non-probability-based sampling.

Findings to date Mean age of the baseline sample was 67.3 years (SD: 7.9 years) and $64 \%$ were women. Two in three adults reported leaving home only for essential purposes in the past week (population-weighted proportion: $69 \%$; $95 \% \mathrm{Cl}: 68 \%$ to $71 \%$ ). Nearly one in five workers aged 55-64 years was placed on a leave of absence or furloughed since the start of the pandemic (17\%; $95 \%$ Cl: $14 \%$ to $20 \%$ ), compared with one in three workers aged $\geq 75$ years ( $31 \%$; $95 \% \mathrm{Cl}: 21 \%$ to $44 \%$ ). Nearly one-third of adults screened positive for each of depression (32\%; $95 \%$ Cl: $30 \%$ to $34 \%)$, anxiety (29\%; $28 \%$ to $31 \%$ ) and loneliness (29\%; $95 \% \mathrm{Cl}: 27 \%$ to $31 \%$ ), with decreasing prevalence of each with increasing age. Future plans Monthly and annual follow-ups of the COVID-19 Coping Study cohort will assess Iongitudinal changes to mental health, cognitive health and wellbeing in relation to social, behavioural, economic and other COVID-19-related changes to life circumstances. Quantitative and in-depth qualitative interview data wil be collected through online questionnaires and telephone interviews. Cohort data will be archived for public use.

\section{INTRODUCTION}

The COVID-19 pandemic has dire immediate and long-term consequences for population health and well-being. Many middle-aged and older adults are not only at elevated risk for severe morbidity and mortality from
Strengths and limitations of this study

- Large sample size of US adults aged $\geq 55$ years with representation from all 50 US states, the District of Columbia and Puerto Rico.

- Longitudinal design with repeated measures of depression, anxiety, loneliness, cognitive health and health behavioural outcomes, allowing the investigation of rapid change over time in these outcomes in relation to COVID-19-related social and economic exposures.

- The internet-based, non-probability sampling design allowed us to rapidly enrol a large cohort during the early months of a major pandemic, but led to underrepresentation of certain sociodemographic groups and non-internet users

- The mixed methods approach provides in-depth qualitative data that add nuance and detail to the epidemiological findings, and which may inform the development of future hypotheses.

COVID-19, but may also be vulnerable to psychological, social and economic harms associated with the pandemic. ${ }^{1-3}$ Physical distancing, a necessary intervention to reduce transmission in the absence of a vaccine, was enacted through shelter-in-place orders and social distancing recommendations across most of the USA beginning in mid-March 2020. ${ }^{4}$ At the same time, a deep economic recession took hold, with a $9.2 \%$ increase in unemployment recorded by the end of May $2020 .^{5}$ Older adults became a key population group of concern during this time, with the highest rates of COVID-19 morbidity and mortality identified among those aged $\geq 65$ years. ${ }^{6}$ Subsequent political and popular media discourse has depicted 'the elderly' as frail, burdensome and disposable. ${ }^{7}$ 
The potentially complex mental health effects of social and economic upheaval during the COVID-19 pandemic are unknown among middle-to-older aged US adults, who experience heterogeneous COVID-19 risk statuses. ${ }^{8}$ While there is relatively little literature on this topic, selfisolation and quarantine during the SARS and Middle East respiratory syndrome pandemics were associated with adverse mental health outcomes. ${ }^{9}{ }^{10}$ These pandemics were short-lived and less severe in scale than COVID-19, with minimal impact in the USA. Emerging evidence indicates elevated prevalence of depression, anxiety and loneliness in younger adults during the COVID-19 pandemic in the USA, ${ }^{11-14}$ yet evidence among middle-aged and older adults remains sparse. ${ }^{15}$ Pre-pandemic evidence indicates that social isolation, negative financial shocks and stress have adverse effects on mental health, cognitive function and well-being among middle-aged and older adults. ${ }^{16-21}$ The specific forms of these exposures during COVID-19 warrant investigation in order to understand the medium-term and long-term effects of the pandemic on middle-aged and older adults' health.

A key form of life disruption due to COVID-19 is the need for physical isolation. Older adults may need to isolate more intensely and for longer than younger groups in order minimise COVID-19 morbidity and mortality in the population, in addition to middleaged adults approaching age 65 years who experience comorbid conditions or other ageing-related conditions that may place them at elevated risk. ${ }^{82}$ This population group may thus experience prolonged periods of physical isolation that health systems, communities and personal social support networks need to be equipped to handle. ${ }^{3}$ However, the current lack of evidence on modifiable factors to support middle-aged and older adults' health and well-being during the COVID-19 pandemic limits the development of targeted, equitable public health strategies to support their short- and long-term health outcomes in the wake of this crisis.

\section{Objectives}

We launched the COVID-19 Coping Study in order to investigate how social and economic changes due to the COVID-19 pandemic impact mental health and well-being of US adults aged 55 years and over. Primary outcomes of interest are depressive symptoms, anxiety symptoms and loneliness. Secondary outcomes are self-rated health, selfrated memory and cognitive health, and life satisfaction. Measures of the primary and secondary outcomes are included at baseline and each study follow-up, in order to assess their associations with social and economic risk and resilience factors of interest cross-sectionally at baseline and longitudinally over time as the pandemic progresses. Risk and resilience factors of interest include: physical isolation and forms of face-to-face and virtual social engagement; changes to living circumstances and household composition; changes to employment and income, especially for those adults approaching and working beyond retirement age; COVID-19 incidence, hospitalisation and mortality among family and friends; coping strategies and changes in lifestyle behaviours; and neighbourhood contextual factors including access to parks and green space, residential segregation and economic affluence and disadvantage. We selected these factors as those which may be most impacted by the pandemic, and which have prior evidence for their relationships with mental health, cognitive health and wellbeing among adults in the study age range ${ }^{16-21}$ The study thus aims to provide data to inform public health strategies to support middle-aged and older adults during and beyond the pandemic. The objective of this cohort profile is to describe the cohort design, recruitment, data collection procedures, measures, and early baseline findings.

\section{COHORT DESCRIPTION \\ Design}

We employed a parallel convergent mixed-methods design in a nationwide longitudinal cohort study, through the collection of quantitative and qualitative data in online surveys and telephone interviews (figure 1). ${ }^{23}$ Eligible participants were adults aged $\geq 55$ years who resided in the USA, including Puerto Rico, and who were able to access and complete the online survey in English or Spanish.

\section{Recruitment strategy}

We used a multi-frame, non-probability online recruitment strategy to enhance coverage of diverse populations and geographic locations. The first sampling frame was the 'snowball sample', which was recruited through social media including Facebook and Instagram distribution and advertisements, organisational mailing lists, the NIH ResearchMatch database, the University of Michigan Health Research database and word-of-mouth snowball sampling in English and Spanish. Because some older adults may be harder to recruit online and through social media, snowball sampling was a key aspect of our recruitment strategy. ${ }^{24}{ }^{25}$ We encouraged study participants to recruit others through word-of-mouth, and we promoted the study to prospective participants as a way of understanding how middle-aged and older adults are coping with the COVID-19 pandemic. The second was the 'panel sample', which was recruited from an online research panel maintained by the professional survey company Dynata (formerly known as Survey Sampling International). We implemented sampling quotas for age, gender, race, ethnicity and education that matched the general US population aged $\geq 55$ years based on the Centers for Disease Control and Prevention's Wideranging Online Data for Epidemiologic Research (CDC WONDER). ${ }^{26}{ }^{27}$ The snowball sample participants did not receive compensation, while panel sample participants received a nominal amount of approximately US $\$ 1$, due to commercial arrangement with the company that maintained the sample. Additional details on recruitment can be found in the online supplemental material. 
Quantitative

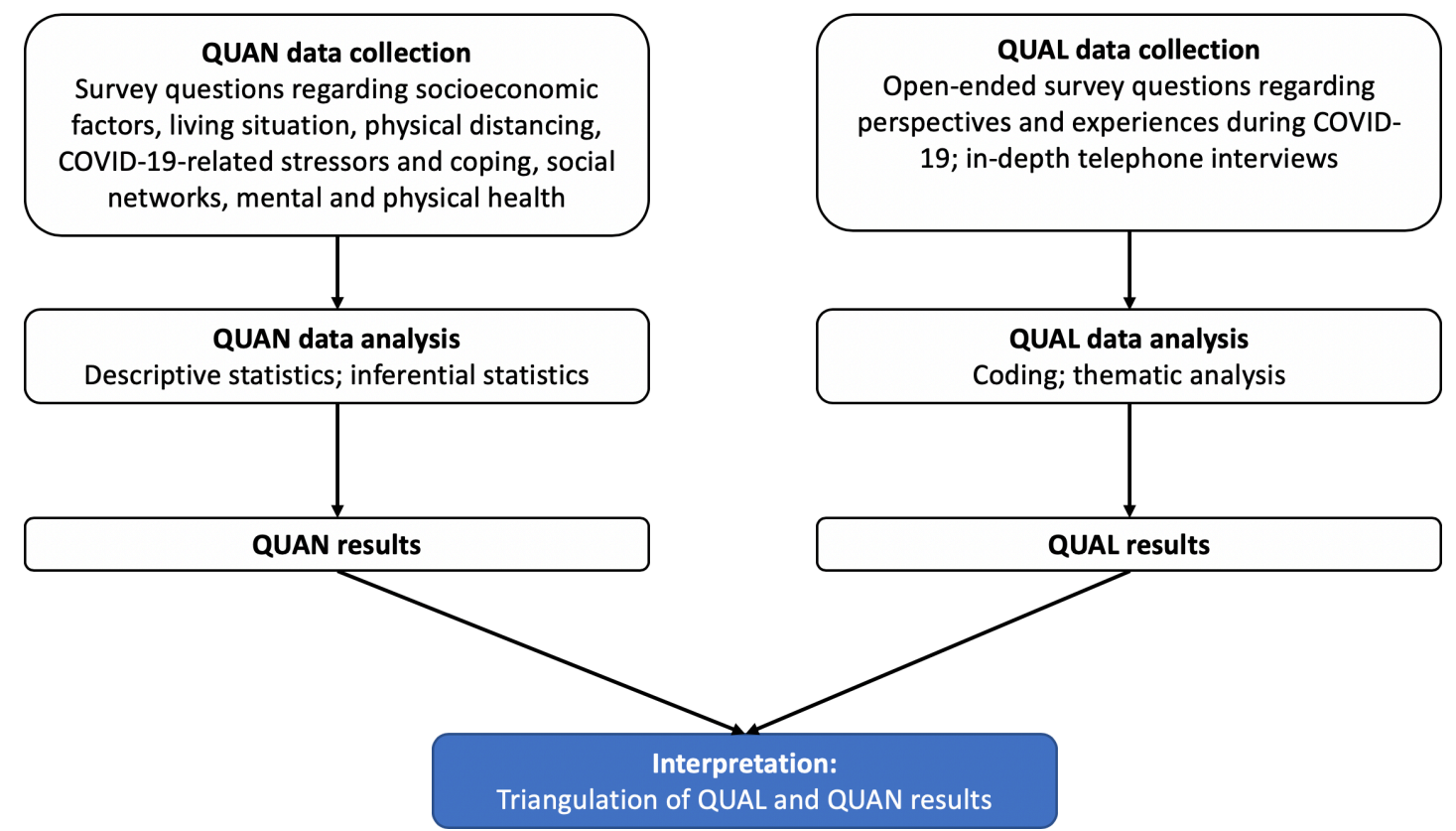

Qualitative

\section{Data collection}

Baseline data were collected through a questionnaire designed to take approximately $17 \mathrm{~min}$ on computer, tablet or smartphone interfaces, administered through the University of Michigan Qualtrics. Participants were given 1 week to complete the questionnaire after starting it. The baseline questionnaire was developed in consultation with survey methodologists at the Survey Research Center at the University of Michigan Institute for Social Research. All study participants provided online informed consent before beginning the questionnaire (see online supplemental material for information sheet and consent form). Participants in the snowball sampling frame were invited to provide their email addresses if they consented to be contacted for follow-ups. Participants will be invited via email to complete brief follow-up questionnaires monthly for 1 year, and annually for 5 years. In Spring 2021, 100 snowball sample participants will be randomly sampled within sociodemographic strata to approximately match general population aged $\geq 55$ years, and invited to complete 45-minute, semi-structured in-depth interviews by telephone or secure video call.

\section{Measures}

\section{Baseline online questionnaire}

The baseline questionnaire collected data on sociodemographic factors, personal COVID-19 testing and symptom history, social network burden of COVID-19 morbidity and mortality (family and friends with symptoms, positive tests, hospitalisation and death due to COVID-19), worry about COVID-19, attitudes towards governmental responses to COVID-19, self-isolation, frequency and types of contacts with family members and friends, changes in daily behaviours, social media use, use of mobility aids, housing conditions and residence zip code (see online supplemental material for full questionnaire). Racial and ethnic group categories were defined according to US Census definitions. ${ }^{28}$ They are presented in this report according to categories of racialised identity, whereby those who identified as multiple races were grouped to a single racial-ethnic category based on the social processes of US racialisation and heightened racial sensitivity and hostility amid the COVID-19 pandemic. ${ }^{29-31}$ We collected baseline data on the following primary and secondary outcomes: depressive symptoms (8-item Center for Epidemiological Studies Depression Scale; CES-D), anxiety symptoms (5-item Beck Anxiety Inventory; BAI), loneliness (3-item UCLA Loneliness Scale), life satisfaction (scale of 0 through 10, from the Gallup World Poll) and self-rated general health and self-rated memory (both 5-point Likert-type scales). ${ }^{32-34}$

Self-reported pre-COVID-19 covariates were as follows: employment status, job industry according to the 2018 Standard Occupational Classification from the U.S. Bureau of Labor Statistics, smoking status, alcohol consumption, moderate-to-vigorous physical activity, physician-diagnosed health conditions, degree of social isolation (using the 5-point social isolation index from the English Longitudinal Study of Ageing ${ }^{35}$ ), usual mode of transportation and usual household co-habitants. Open-ended qualitative questionnaire measures inquired about strategies that respondents were taking to help them cope with the COVID-19 pandemic, and any other experiences during the COVID-19 pandemic that they wanted to share. 


\section{Follow-up online questionnaires}

The content of the follow-up questionnaires varies monthto-month, as certain items are rotated and the content is informed by emergent themes in participant responses to previous questionnaires and developments in the COVID-19 pandemic (online supplemental table 1). All monthly and annual follow-up questionnaires will include the primary and secondary study outcomes. ${ }^{32-34}$ The Patient-Reported Outcomes Measurement Information System Applied Cognition (General Concerns and Abilities) 6-item scales are included at the 4-month follow-up and all subsequent even-numbered monthly follow-ups. ${ }^{36}$ The question rotations are intended to reduce questionnaire length and repetitiveness for the participants, as an effort to minimise attrition. The follow-up questionnaires are available as they are fielded (https://sph.umich.edu/ covid19copingstudy/).

\section{Follow-up in-depth interviews}

The in-depth interviews will aim to deepen understanding of participants' experiences and perspectives during the COVID-19 pandemic. Semi-structured questions in telephone or secure video calls will probe about secondary health outcomes related to the social, behavioural and economic impacts of COVID-19. We will ask about altered daily routines, social engagement, service provision and the neighbourhood environment. Questions will also probe for psychosocial strengths, coping strategies and community resources used to cope with adversity during the pandemic. In addition to audio and/or visual recordings, interviewers will record notes during and after the interview. The post-interview field note guide will track progress (eg, duration, any interruptions or technical problems) and describe interviewer impressions (eg, discomfort with certain topics, emotional responses), non-verbal behaviour (eg, tone of voice, facial expression) and preliminary analysis (eg, interviewer's questions, emerging patterns and insights). ${ }^{37}$

\section{Population weights}

Given the non-probability nature of this sample, we developed population weights to reduce potential selection and other non-sampling biases, such as coverage and non-response. ${ }^{38} 39$ The sample data were calibrated to population totals estimated by the 2018 American Community Survey 1-year estimates with respect to selected sociodemographic dimensions. ${ }^{40}$ To maximise potential bias reduction and improve SEs, these dimensions were selected by analysing which main effects and interactions were most predictive of the primary study outcomes (depression, anxiety and loneliness) in a multiple logistic regression model. ${ }^{39}$ This analysis identified that the main effects of age group (55-59 years; $60-64$ years; 65-69 years; 70-74 years; 75-79 years; 80-84 years; $85+$ years), education (less than high school; high school diploma or equivalency; some college or 2-year associate's degree; 4-year college or university degree; postgraduate or professional degree), race/ethnicity (non-Hispanic: white; non-Hispanic black; non-Hispanic: Asian; nonHispanic: other races; Hispanic: white; Hispanic: other races), Census division (New England; Middle Atlantic; East North Central-Michigan; East North Centralothers; West North Central; South Atlantic; East South Central; West South Central; Mountain; Pacific) and the interaction between sex (female; male) and marital status (single, never married; single, divorced/separated; single, widowed; married or in a relationship) would accomplish the goals of selection bias reduction through population weighting. The East North Central census division was subdivided into the state of Michigan and other states, given the over-representation of Michigan due to the recruitment in the snowball sample. Missing values on sex, marital status and census division were imputed through multivariate imputation by chained equations, implemented in the mice package in R, using age group, sex, education and race/ethnicity as covariates. ${ }^{41}$ The calibration was conducted using a raking procedure over the selected dimensions listed above, using the rake function of the survey package in $\mathrm{R}^{38}{ }^{42-44}$ Three sets of weights were created: one for the overall study sample ('snowball' + 'panel'), one for the snowball sample and one for the panel sample. After evaluating the distribution of the weights, the weights for the snowball sample were trimmed at the top third percentile.

\section{Participant and patient involvement}

The study participants and the public did not take part in the study design or choice of baseline questionnaire measures. However, word-of-mouth snowball recruitment was a key recruitment strategy, as we aimed to maximise inclusion of those who may not have originally seen the study through social media or the other online sources where we 'seeded' the study distribution. ${ }^{24} 25$ The study participants were thus deeply involved in the recruitment and conduct of the study. We have used direct participant email communication and emergent themes from analysing the qualitative open-ended responses at early time points to inform the selection of measures for the subsequent follow-ups. We are disseminating early study results to participants in monthly newsletters, and inviting responses and suggestions via email. Participant responses to the results shown in our newsletters have included sentiments about the pandemic, altered daily life and concurrent social, economic and political events, and have informed our follow-up measures.

\section{Statistical analyses}

We described the baseline characteristics of the COVID-19 Coping Study sample using basic descriptive statistics, overall and according to sampling frame, with and without population weights applied. We estimated the population-weighted distributions of self-reported effects of the COVID-19 pandemic on aspects of daily life and employment, mental health outcomes (depression; anxiety; loneliness), overall and by age group (55-64 years, 65-74 years and 75+ years). The map of participant 
Snowball sampling frame

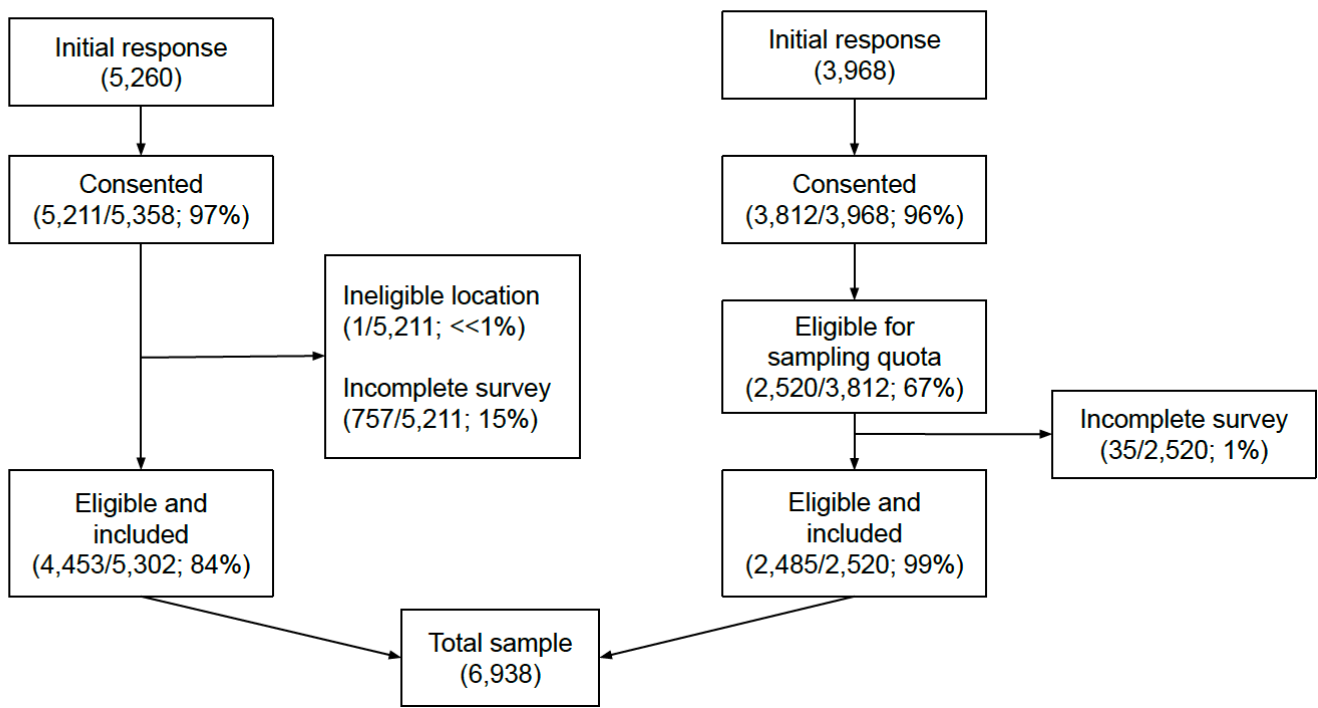

Figure 2 Study recruitment flow diagram, COVID-19 Coping Study, USA, from 2 April to 31 May 2020.

responses was created using ArcGIS Online (Redlands, California, USA), and all other statistical analyses were conducted using Stata/SE V.16.0 (College Station, Texas, USA) and R V.4.0.0 (Vienna, Austria).

\section{RESULTS}

\section{Sample characteristics}

A total of 4453 participants were recruited in the snowball sampling frame from 2 April to 31 May 2020, with 4401 questionnaires completed in English and 52 in Spanish. A total of 2485 were recruited in the panel sampling frame from 17 April to 15 May 2020, for a total of 6938 participants (figure 2). The majority of snowball sample participants provided their email address for follow-ups (95\%; 4211/4453). Participants resided in all 50 US states, the District of Columbia and Puerto Rico (figure 3). The median questionnaire completion time was $16.3 \mathrm{~min}$ (IQR: 12.5-22.0 min). Mean age of the baseline sample was 67.3 years (SD: 7.9; range: 55-110), $64 \%$ were women $(4437 / 6938), 84 \%$ were non-Hispanic white (5858/6938), 6\% were non-Hispanic black or African American (383/6938), 5\% were Hispanic or

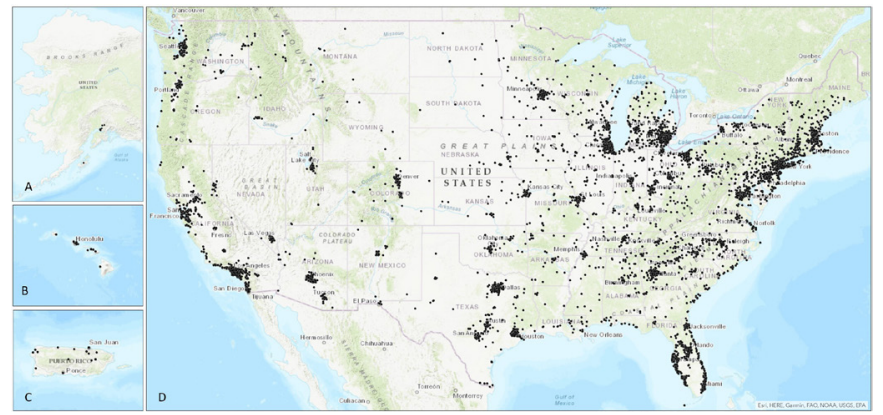

Figure 3 Map of participant responses, COVID-19 Coping Study, USA, from 2 April to 31 May 2020. (A) Alaska; (B) Hawaii; (C) Puerto Rico; (D) contiguous USA.
Latinx (349/6938), 2\% were East Asian, Native Hawaiian or another Pacific Islander (165/6938) and 3\% were of another racial or ethnicity minority group (183/6938; table 1). Half of respondents were retired (3598/6933; $52 \%)$, one-quarter lived alone $(1799 / 6880 ; 26 \%)$, nearly half owned their home outright $(3239 / 6938 ; 47 \%), 1$ in 10 used a mobility aid $(578 / 6778 ; 9 \%)$ and over half reported at least one diagnosed chronic health condition (table 1). Within the snowball sample, participant characteristics were similar across recruitment sources (online supplemental table 2). Missing data were rare, with $<5 \%$ of observations missing for all variables and $\leq 2 \%$ observations missing for key sociodemographic and primary outcome variables (table 1 ).

Table 2 describes the overall and age-specific population-weighted self-reported impacts of COVID-19 on daily life and employment. The corresponding unweighted distributions are shown in online supplemental table 3. The majority of respondents were 'moderately' or 'extremely' worried about the COVID-19 pandemic (table 2). Less than $1 \%$ reported testing positive for COVID-19, while $8 \%$ of those aged 55-64 years (95\% CI: $7 \%$ to $10 \%$ ), $8 \%$ of those aged $65-74$ years (95\% CI: $7 \%$ to $10 \%$ ) and $3 \%$ of those aged $75+$ years (95\% CI: $2 \%$ to $4 \%$ ) reported recently having COVID19-like symptoms (table 2). Respondents' social network burdens of COVID-19 infection and mortality were higher in the younger age groups, with approximately twice as many people in the 55-64 years age group as in the $75+$ years age group reporting having friends or family with COVID-19 symptoms, a positive test, hospitalisation or mortality (table 2). Among those who were working prior to the COVID-19 pandemic, the reported effects of the pandemic on employment were strongly graded by age (table 2). Approximately two in three adults across all age groups reported leaving their home 
Table 1 Baseline characteristics of the COVID-19 Coping Study, USA, from 2 April to 31 May 2020

\begin{tabular}{|c|c|c|c|c|}
\hline & Total (weighted) & Total (unweighted) & $\begin{array}{l}\text { Snowball sample } \\
\text { (unweighted) }\end{array}$ & $\begin{array}{l}\text { Panel sample } \\
\text { (unweighted) }\end{array}$ \\
\hline & $\mathrm{n}=95778123$ & $\mathrm{n}=6938$ & $\mathrm{n}=4453$ & $\mathrm{n}=2485$ \\
\hline Baseline characteristics & $\%(95 \% \mathrm{Cl})$ & n (\%) & n (\%) & n (\%) \\
\hline Age, mean (SD; range; $n=6938)$ & $67.8(67.3$ to 68.2$)$ & $67.3(7.9 ; 55-110)$ & $67.2(7.5 ; 55-99)$ & $67.4(8.5 ; 55-110)$ \\
\hline \multicolumn{5}{|l|}{ Sex $(n=6938)$} \\
\hline Male & $46 \%(44 \%$ to $48 \%)$ & $2492(36)$ & $1250(28)$ & $1242(50)$ \\
\hline Female & $54 \%(52 \%$ to $56 \%)$ & $4437(64)$ & $3194(72)$ & $1243(50)$ \\
\hline Other or prefer not to say & $<1 \%$ & $9(<1)$ & $9(<1)$ & - \\
\hline \multicolumn{5}{|l|}{ Racialised identity* $(n=6938)$} \\
\hline Non-Hispanic white & $73 \%(71 \%$ to $74 \%)$ & $5858(84)$ & $4056(91)$ & $1802(73)$ \\
\hline Non-Hispanic black or African American & $10 \%(9 \%$ to $12 \%)$ & $383(6)$ & $115(3)$ & $268(11)$ \\
\hline Hispanic or Latinx & $11 \%(9 \%$ to $12 \%)$ & $349(5)$ & $126(3)$ & $223(9)$ \\
\hline East Asian, Native Hawaiian or Pacific Islander & $4 \%(3 \%$ to $5 \%)$ & $165(2)$ & $42(1)$ & $123(5)$ \\
\hline American Indian or Alaska Native & $1 \%(1 \%, 1 \%)$ & $73(1)$ & $41(1)$ & $32(1)$ \\
\hline Asian Indian & $<1 \%$ & $33(<1)$ & $15(<1)$ & $18(1)$ \\
\hline Other & $1 \%(1 \%$ to $1 \%)$ & $77(1)$ & $58(1)$ & $19(1)$ \\
\hline \multicolumn{5}{|l|}{ Education ( $\mathrm{n}=6938)$} \\
\hline High school or equivalent or less & $44 \%(42 \%$ to $46 \%)$ & $1199(17)$ & $157(4)$ & $1042(42)$ \\
\hline Some college or 2-year associate's degree & $28 \%(26 \%$ to $29 \%)$ & $1386(20)$ & $715(16)$ & $671(27)$ \\
\hline Four-year college or university degree & $16 \%(15 \%$ to $17 \%)$ & $1902(27)$ & $1435(32)$ & $467(19)$ \\
\hline Post-graduate or professional degree & $12 \%(11 \%$ to $13 \%)$ & $2451(35)$ & $2146(48)$ & $305(12)$ \\
\hline \multicolumn{5}{|l|}{ Employment status (pre-COVID-19; $n=6933$ ) } \\
\hline Retired $\dagger$ & $53 \%(51 \%$ to $55 \%)$ & $3598(52)$ & $2276(51)$ & $1322(53)$ \\
\hline Employed full-time & $18 \%(17 \%$ to $20 \%)$ & $1570(23)$ & $1056(24)$ & $514(21)$ \\
\hline Employed part-time & $7 \%(7 \%$ to $8 \%)$ & $642(9)$ & $459(10)$ & $183(7)$ \\
\hline Self-employed & $6 \%(5 \%$ to $6 \%)$ & $483(7)$ & $351(8)$ & $132(5)$ \\
\hline Unable to work (disability or health condition) & $8 \%(7 \%$ to $9 \%)$ & $329(5)$ & $172(4)$ & $157(6)$ \\
\hline Homemaker or family caregiver & $5 \%(4 \%$ to $6 \%)$ & $207(3)$ & $96(2)$ & $111(4)$ \\
\hline Unemployed, seeking work & $3 \%(2 \%$ to $4 \%)$ & $104(2)$ & $41(1)$ & $63(3)$ \\
\hline \multicolumn{5}{|l|}{ Marital status $(n=6920)$} \\
\hline Married or in a relationship & $59 \%(57 \%$ to $61 \%)$ & $4542(66)$ & $2975(67)$ & $1567(63)$ \\
\hline Single, never married & $8 \%(7 \%$ to $9 \%)$ & $572(8)$ & $330(7)$ & $242(10)$ \\
\hline Single, divorced or separated & $18 \%(16 \%$ to $20 \%)$ & $1145(17)$ & $746(17)$ & $399(16)$ \\
\hline Single, widowed & $15 \%(14 \%$ to $17 \%)$ & $661(10)$ & $395(9)$ & $266(11)$ \\
\hline Lives alone $(n=6880)$ & $28 \%(26 \%$ to $30 \%)$ & $1799(26)$ & $1170(26)$ & $629(26)$ \\
\hline \multicolumn{5}{|l|}{ Housing tenure $(n=6921)$} \\
\hline Owned outright & $42 \%(40 \%$ to $44 \%)$ & $3239(47)$ & $2071(47)$ & $1168(47)$ \\
\hline Owned with mortgage & $31 \%(29 \%$ to $32 \%)$ & $2523(36)$ & $1776(40)$ & $747(30)$ \\
\hline Rented (market rental) & $18 \%(16 \%$ to $19 \%)$ & $792(11)$ & $409(9)$ & $383(15)$ \\
\hline Rented (subsidised housing) & $5 \%(4 \%$ to $6 \%)$ & $162(2)$ & $52(1)$ & $110(4)$ \\
\hline Living rent-free or other & $5 \%(4 \%$ to $6 \%)$ & $205(3)$ & $133(3)$ & $72(3)$ \\
\hline Uses a mobility aid $(n=6778)$ & $11 \%(10 \%$ to $13 \%)$ & $578(9)$ & $317(7)$ & $261(11)$ \\
\hline \multicolumn{5}{|l|}{ Previous physician diagnoses: $(n=6938)$} \\
\hline Hypertension & $52 \%(50 \%$ to $53 \%)$ & $3154(45)$ & $1898(43)$ & $1256(51)$ \\
\hline Diabetes & $17 \%(16 \%$ to $19 \%)$ & $941(14)$ & $514(12)$ & $427(17)$ \\
\hline Heart disease & $10 \%(9 \%$ to $11 \%)$ & $654(9)$ & $443(10)$ & $211(8)$ \\
\hline
\end{tabular}




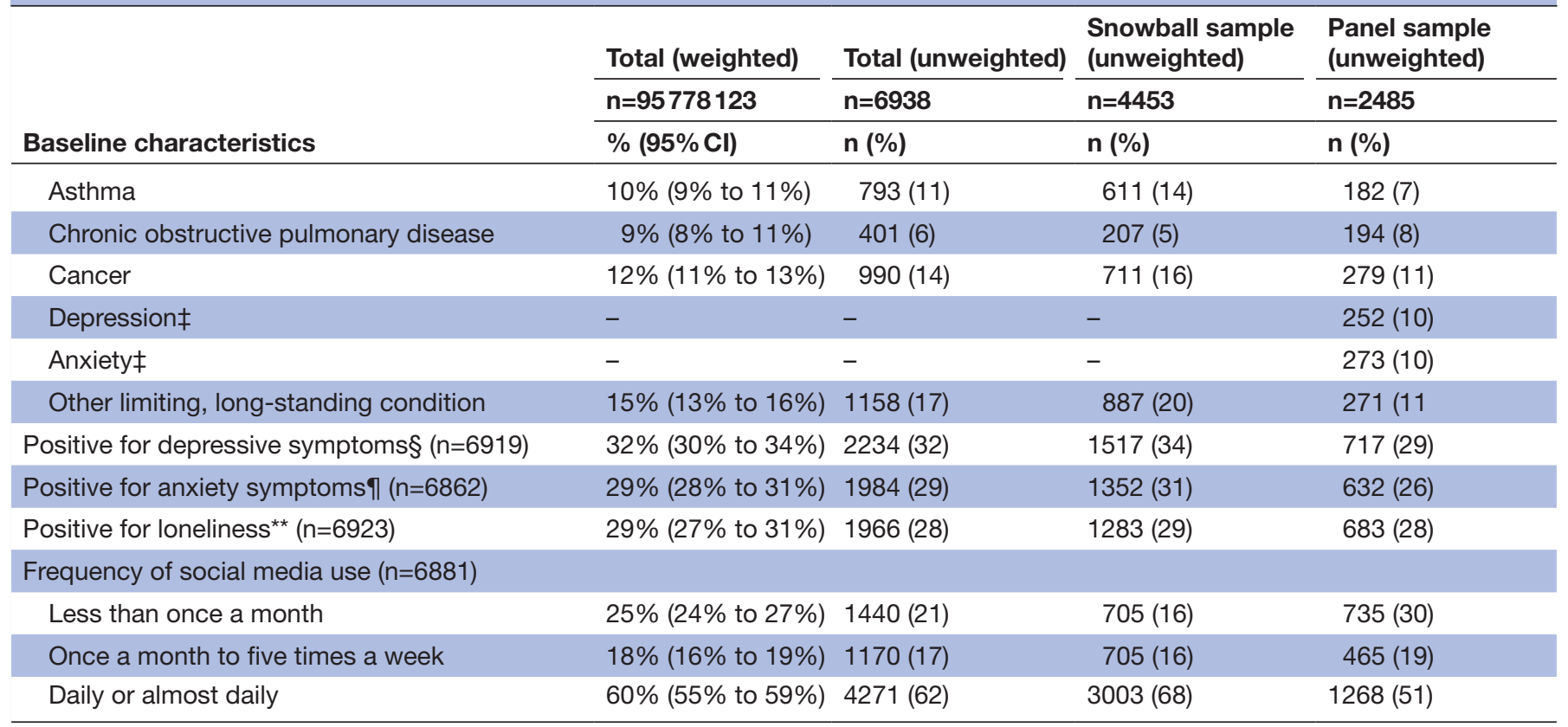

*Racialised identity was created to group those who identified as multiple races with a single racial-ethnic category based on processes of US racialisation and heightened racial sensitivity and hostility amid the COVID-19 pandemic. †Eight respondents who reported they were in school were grouped into the 'Retired' category. $\ddagger$ Previous physician diagnoses of depression and anxiety were not assessed in the snowball sample at baseline. $\S 8$-item Center for Epidemiological Studies Depression Scale score $\geq 3$. १5-item Beck Anxiety Inventory Scale score $\geq 10$.

**3-item UCLA Loneliness Scale score $\geq 6$.

only for essential purposes every day in the past week, with minimal age differences (table 2).

The baseline prevalence of depression, anxiety and loneliness was strongly graded by age (figure 4 ). The prevalence of depression declined from $41 \%$ in the $55-64$ years age group (95\% CI: $38 \%$ to $44 \%$ ) to $20 \%$ in the $75+$ years age group (95\% CI: $17 \%$ to $23 \%$ ). Anxiety prevalence declined from $36 \%$ of those aged 55-64 years (95\% CI: $33 \%$ to $38 \%$ ) to $19 \%$ of those aged $75+$ years (95\% CI: $16 \%$ to $23 \%$ ). The prevalence of 'high' loneliness declined from $35 \%$ of those aged 55-64 years (95\% CI: $33 \%$ to $38 \%$ ) to $20 \%$ of those aged $75+$ years (95\% CI: $17 \%$ to $24 \%$ ). All three scales had good internal consistency, with Chronbach's alpha of 0.82 for the 8-item CES-D (depression), 0.75 for the 5-item BAI (anxiety), and 0.77 for the 3-item UCLA loneliness scale.

\section{DISCUSSION}

Many middle-aged and older adults may be at elevated risk not only for severe COVID-19 morbidity and mortality but also adverse psychological, social and economic consequences of the pandemic. ${ }^{12711}$ We established the COVID-19 Coping Study to provide publicly available data on the mental health and well-being of middleaged and older adults as affected by social and economic changes during the COVID-19 pandemic. A total of 6938 study participants aged $\geq 55$ years took part across all 50
US states, the District of Columbia and Puerto Rico. This study will provide rich longitudinal quantitative and qualitative data on physical isolation, social and economic changes, living circumstances, COVID-19 symptom and testing history, health behaviours and a range of mental health, cognitive health and well-being outcomes. The COVID-19 Coping Study may provide timely evidence to inform policy interventions to support mental health and coping throughout the pandemic, such as digital technologies for connectivity, enhanced mental health service provision, public education campaigns and socially supportive municipal infrastructures. ${ }^{2}$

Pre-pandemic data from the nationally representative US Health and Retirement Study (HRS) and National Social Life, Health and Aging Project (NSHAP) indicate a slight U-shaped pattern in depressive symptoms and loneliness with increasing age beyond 50 years and 65 years, respectively. ${ }^{45}{ }^{46}$ We observed decreased prevalence with increasing age, consistent with other emerging data from the early pandemic period ${ }^{47}$ In the National Epidemiologic Survey on Alcohol and Related Conditions (NESARC) in 2004/2005, the prevalence of any anxiety disorder according to the Diagnostic and Statistical Manual of Mental Disorders, fourth edition (DSMIV) criteria among adults aged $\geq 55$ years was $11.39 \%{ }^{48}$ Prevalence in the NESARC declined with age, consistent with our data, although we observed a higher prevalence 
Table 2 Self-reported impacts of COVID-19 on daily life, by age group, COVID-19 Coping Study, USA, from 2 April to 31 May 312020 , population-weighted using 2018 American Community Survey data

\begin{tabular}{|c|c|c|c|c|}
\hline \multirow[b]{3}{*}{ Characteristics } & \multirow[b]{2}{*}{ Overall (weighted) } & \multicolumn{3}{|l|}{ Age group } \\
\hline & & 55-64 years & $65-74$ years & $75+$ years \\
\hline & $\%(95 \% \mathrm{Cl})$ & $\%(95 \% \mathrm{Cl})$ & $\%(95 \% \mathrm{Cl})$ & $\%(95 \% \mathrm{Cl})$ \\
\hline \multicolumn{5}{|l|}{ COVID-19-related impacts on daily life } \\
\hline \multicolumn{5}{|l|}{ Worry about the COVID-19 pandemic } \\
\hline Not at all worried & 5 (4 to 6$)$ & 5 (4 to 6$)$ & 5 (4 to 7$)$ & $6(4$ to 9$)$ \\
\hline Slightly worried & $13(12$ to 14$)$ & 14 (12 to 16$)$ & 10 (9 to 12$)$ & 15 (12 to 18$)$ \\
\hline Somewhat worried & 18 (16 to 19$)$ & $16(14$ to 18$)$ & 20 (18 to 23$)$ & 17 (14 to 20$)$ \\
\hline Moderately worried & 32 (31 to 34 ) & 30 (28 to 33 ) & 34 (31 to 37$)$ & 34 (30 to 38 ) \\
\hline Extremely worried & 32 (30 to 34$)$ & 35 (32 to 38$)$ & 31 (28 to 33 ) & 28 (24 to 33 ) \\
\hline \multicolumn{5}{|l|}{ Personal COVID-19 history } \\
\hline Tested positive for COVID-19 & $<1$ & 1 (1 to 2$)$ & $<1$ & $<<1$ \\
\hline Not tested, but had COVID-19-like symptoms* & $7(6$ to 8$)$ & $8(7$ to 10$)$ & $8(7$ to 10$)$ & $3(2$ to 4$)$ \\
\hline \multicolumn{5}{|l|}{ Social network COVID-19 burden $\dagger$} \\
\hline Tested positive for COVID-19 & 8 (7 to 9$)$ & $9(8$ to 11$)$ & 8 (7 to 9$)$ & 5 (3 to 6$)$ \\
\hline Not tested, but had COVID-19-like symptoms* & 8 (7 to 9$)$ & 10 (9 to 12$)$ & 8 (7 to 9$)$ & 4 (3 to 6$)$ \\
\hline Hospitalised due to COVID-19 & $4(4$ to 5$)$ & $6(5$ to 7$)$ & 4 (3 to 5$)$ & $2(1$ to 4$)$ \\
\hline Passed away due to COVID-19 & 3 (2 to 3$)$ & $4(3$ to 5$)$ & 3 (2 to 4$)$ & 1 (1 to 2$)$ \\
\hline \multicolumn{5}{|c|}{ Effects of COVID-19 on employment (among those in work prior to COVID-19)‡ } \\
\hline Lost job & 6 (5 to 8$)$ & 7 (6 to 9$)$ & 5 (4 to 8$)$ & 2 (1 to 12$)$ \\
\hline Furloughed or placed on leave of absence & 19 (16 to 21$)$ & 17 (14 to 20$)$ & 19 (16 to 24$)$ & 31 (21 to 44$)$ \\
\hline Reduced work hours or income & 24 (22 to 27$)$ & 24 (21 to 28$)$ & 27 (22 to 32 ) & 16 (10 to 25$)$ \\
\hline Working from home & 30 (27 to 32$)$ & 30 (28 to 33$)$ & 30 (26 to 34$)$ & 19 (12 to 28$)$ \\
\hline Work not affected & 26 (23 to 28$)$ & 25 (22 to 29$)$ & 24 (20 to 29) & $35(23$ to 50$)$ \\
\hline \multicolumn{5}{|l|}{ Days spent self-isolating in the past week§ } \\
\hline 0 day & $9(7$ to 10$)$ & 10 (8 to 12$)$ & 7 (5 to 9$)$ & $8(6$ to 11$)$ \\
\hline $1-3$ days & 9 (8 to 10$)$ & $9(7$ to 11$)$ & $9(7$ to 11$)$ & $9(7$ to 11$)$ \\
\hline $4-6$ days & $13(12$ to 15$)$ & $14(12$ to 16$)$ & 12 (10 to 14$)$ & $13(10$ to 16$)$ \\
\hline 7 days & 69 (68 to 71$)$ & 67 (64 to 70 ) & 72 (69 to 75$)$ & 70 (66 to 74 ) \\
\hline Unweighted $\mathrm{n}$ & 6938 & 2861 & 2779 & 1298 \\
\hline
\end{tabular}

*COVID-19-like symptoms were described as a recent 'cough, fever or other influenza-like symptoms'.

†Defined as having at least one family member or friend with each of the outcomes listed. The column totals exceed $100 \%$, as responses were non-mutually exclusive to account for individuals having family members or friends in more than one category. $\ddagger$ The column totals exceed $100 \%$, as responses were non-mutually exclusive to account for multiple changes to employment.

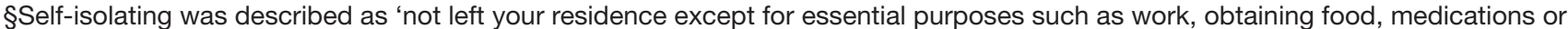
other supplies, outdoor exercise or taking care of pets'.

of anxiety symptomology at all ages in this study. A recent meta-analysis of anxiety disorder prevalence among older adults indicated under-diagnosis in this age range. ${ }^{49}$ Longitudinal data from our study will be valuable for assessing the effects of specific pandemic-related exposures on changes in mental health symptomology and outcomes, and can be triangulated in the future against data from ongoing cohorts like the HRS and NSHAP. ${ }^{50}$

As evidenced by the Domestic Public Health Response to COVID-19, public health interventions often support the interests of population groups who are likely to fully recover from COVID-19. ${ }^{51}$ This excludes the specific needs of older adults, who are at higher risk of severe COVID-19 morbidity and mortality, and may perpetuate age-based health disparities. The present study collects open-ended participant reflections on factors that are influencing their mental health, and how they are addressing stressors and life changes related to the ongoing pandemic. These qualitative data recognise that identity markers, such as ethnicity, race, gender, income and language, are not independent of one another, but rather can create a complex convergence of oppression and disparity if left unacknowledged. ${ }^{52}$ Effective interventions must address multiple intersecting dimensions of identity, positionality and social systems. Evidence on how these intersections are related to health inequities brought about and 


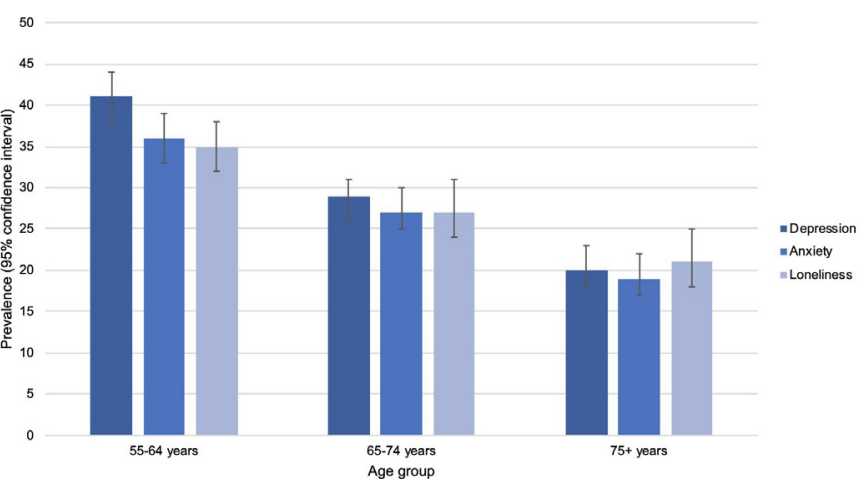

Figure 4 Population-weighted prevalence of depression (8-item Center for Epidemiological Studies Depression Scale score $\geq 3$ ), anxiety (5-item Beck Anxiety Inventory Scale score $\geq 10$ ) and loneliness (3-item UCLA Loneliness Scale score $\geq 6$ ), by age group. Error bars represent 95\% Cls. Differences between age groups are statistically significant at $p<0.05$ for each outcome.

exacerbated by the COVID-19 pandemic will strengthen efforts to support diverse middle-aged and older adults throughout and after the pandemic.

\section{Strengths and limitations}

The COVID-19 Coping Study has some important limitations. This study was launched during the first upswing of a major pandemic, and did not capture people who may have been too sick to take part in the study, such as those who were hospitalised with COVID-19 or other health conditions. In our upcoming reports, we will compare our study sample prevalence of COVID-19 to published population data to evaluate and correct for any bias this may introduce into our estimates, as appropriate. Men, older adults from racial and ethnic minority groups, Spanish speakers and those with high school education or less were under-represented in the snowball sampling frame relative to the general population. This may limit sample size for some stratified analyses, and may affect internal validity for certain analyses if these factors are correlated with a given exposure and outcome under study. The population weights we generated using the American Community Survey data should reduce any potential selection bias due to these and other sociodemographic factors in estimates of the primary mental health outcomes under study. However, the weights may not account for unmeasured drivers of sample selection, and may not necessarily allow the estimation of populationrepresentative prevalence estimates.

All study data were self-reported and subject to recall error. Missing data among completed questionnaires were uncommon, with most variables being complete or having less than $5 \%$ of observations missing. We recruited for this study and collected data using online methods, so our findings may not be generalisable to non-internet users. Although internet use is high among older adults in the USA, especially when considering access to mobile data through smartphones, individuals unable to use the internet during the recruitment period due to barriers such as illness, disability or financial access could not participate..$^{53}$ While our snowball sampling recruitment method was intended to enhance coverage of individuals who do not use the internet or social media very often, this strategy assumes sufficient social network intensity between those who are and who are not on social media. However, the online modality allowed us to rapidly conduct this research at a low cost during a rapidly unfolding pandemic that limited physical interaction and affected people's lives in dramatic ways. We experienced strong snowball-based recruitment for this study, indicating the public's willingness to take part in COVID-19 research at a time when daily life has been disrupted at unprecedented levels in the USA and around the world.

Strengths of this study include its national coverage, large sample size, quantitative and qualitative mixedmethods approach and ability to longitudinally track within-person changes in mental health and wellbeing among middle-aged and older adults during the COVID-19 pandemic. Individual-level data are linked to geographic identifiers, which enables future analyses of area-level exposures including racial residential segregation, poverty, service access, COVID-19 burden and pandemic control policy changes. Our data collection overlapped with nationwide Black Lives Matter protests against racism and police violence sparked by several murders including those of George Floyd, Breonna Taylor and Ahmaud Arbery between February and May 2020. ${ }^{54}$ While not presented in this report, we have observed in-depth reactions to these events in the open-ended questionnaire responses. We will analyse these qualitative data in relation to changes in mental health outcomes following these events. Our use of qualitative and quantitative approaches can help generate novel hypotheses on how social, political, economic and public health circumstances in the USA affect middle-aged and older adults' mental health. ${ }^{45} 5556$

\section{CONCLUSION}

The COVID-19 Coping Study is a nationwide, longitudinal mixed-methods cohort study that aims to identify the effects of social and economic upheaval during the COVID-19 pandemic on mental health, cognitive health and well-being among US adults aged $\geq 55$ years. Our baseline data indicate substantial self-reported effects of COVID-19 on daily life and employment among middleaged and older US adults, and prevalent age-graded mental health symptoms during the first upswing of the pandemic in this population group. The COVID-19 Coping Study will provide needed empirical evidence on the specific challenges and resiliencies of middle-aged and older adults during the pandemic. Results may inform equitable public health interventions to harness positive coping strategies, foster social support and encourage meaningful daily activities among ageing populations during times of stress and trauma. 


\section{COLLABORATION}

We welcome potential collaborators to work with the COVID-19 Coping Study or related research on the mental health of middle-aged and older adults as affected by the COVID-19 pandemic. As of early 2021, our deidentified, non-geographic data may be securely accessed through reasonable request and collaboration with the study team. Please contact LCK (lkob@umich.edu) or JMF (jmfinlay@umich.edu). We request that potential collaborators complete a data confidentiality and use agreement, in addition to a proposal form to ensure nonoverlap of ongoing scientific publications (available from LCK or JMF).

\section{Author affiliations}

${ }^{1}$ Center for Social Epidemiology and Population Health, Department of Epidemiology, University of Michigan School of Public Health, Ann Arbor, Michigan, USA

${ }^{2}$ Survey Research Center, University of Michigan Institute for Social Research, Ann Arbor, Michigan, USA

${ }^{3}$ Department of Neurobiology, Harvard Medical School, Boston, Massachusetts, USA ${ }^{4}$ Department of Health Management and Policy, University of Michigan School of Public Health, Ann Arbor, Michigan, USA

${ }^{5}$ Social Environment and Health Program, Survey Research Center, University of Michigan Institute for Social Research, Ann Arbor, Michigan, USA

\section{Twitter Lindsay C Kobayashi @EpiKobayashi}

Acknowledgements We are thankful to the COVID-19 Coping Study participants, who took time out of their lives to share their experiences and perspectives with us. We gratefully acknowledge the following individuals for their advice in developing the COVID-19 Coping Study design and questionnaire measures: Zachary Baker, Robyn Birkeland, Philippa Clarke, Jorge Andres Escobar, Marti DeLiema, Joseph Gaugler, Carina Gronlund, Lisa Holland, Hayley McCarron, Lauren Mitchell, Manka Nkimberg, Ivette C. Palavicino, Colleen Peterson and Tamara Statz.

Contributors LCK and JMF conceived of, designed and supervised the COVID-19 Coping Study. RN and CBP-M contributed to the study design. JSK and CBP-M conducted data collection. BQO, LCK and RN conducted the statistical analyses. JSK and MRE contributed to the statistical analyses. LCK, JMF, RN and YRV drafted the manuscript. All authors contributed to the interpretation of data, revision of the manuscript for important intellectual content and have read and approved of the final version of the manuscript.

Funding The authors have not declared a specific grant for this research from any funding agency in the public, commercial or not-for-profit sectors.

Map disclaimer The depiction of boundaries on this map does not imply the expression of any opinion whatsoever on the part of BMJ (or any member of its group) concerning the legal status of any country, territory, jurisdiction or area or of its authorities. This map is provided without any warranty of any kind, either express or implied.

Competing interests None declared.

Patient consent for publication Not required.

Ethics approval The University of Michigan Health Sciences and Behavioral Sciences Institutional Review Board approved the COVID-19 Coping Study protocol (HUM00179632).

Provenance and peer review Not commissioned; externally peer reviewed.

Data availability statement Data are available upon reasonable request. Deidentified non-geographic data are available upon reasonable request through collaboration. Please contact LCK (Ikob@umich.edu) or JMF (jmfinlay@umich. edu). In 2021, the study data will be archived for public use at the Inter-university Consortium for Political and Social Research (ICPSR), maintained by the Institute for Social Research at the University of Michigan.

Supplemental material This content has been supplied by the author(s). It has not been vetted by BMJ Publishing Group Limited (BMJ) and may not have been peer-reviewed. Any opinions or recommendations discussed are solely those of the author(s) and are not endorsed by BMJ. BMJ disclaims all liability and responsibility arising from any reliance placed on the content. Where the content includes any translated material, BMJ does not warrant the accuracy and reliability of the translations (including but not limited to local regulations, clinical guidelines, terminology, drug names and drug dosages), and is not responsible for any error and/or omissions arising from translation and adaptation or otherwise.

Open access This is an open access article distributed in accordance with the Creative Commons Attribution Non Commercial (CC BY-NC 4.0) license, which permits others to distribute, remix, adapt, build upon this work non-commercially, and license their derivative works on different terms, provided the original work is properly cited, appropriate credit is given, any changes made indicated, and the use is non-commercial. See: http://creativecommons.org/licenses/by-nc/4.0/.

\section{ORCID iD}

Lindsay C Kobayashi http://orcid.org/0000-0003-2725-3107

\section{REFERENCES}

1 Shahid Z, Kalayanamitra R, McClafferty B, et al. COVID-19 and older adults: what we know. J Am Geriatr Soc 2020;68:926-9.

2 Morrow-Howell N, Galucia N, Swinford E. Recovering from the COVID-19 pandemic: a focus on older adults. J Aging Soc Policy 2020;32:526-35.

3 Armitage R, Nellums LB. COVID-19 and the consequences of isolating the elderly. Lancet Public Health 2020;5:e256.

4 Mervosh S, Lu D, Swales V. See which states and cities have told residents to stay at home. The New York Times. Available: https:// www.nytimes.com/interactive/2020/us/coronavirus-stay-at-homeorder.html [Accessed 16 Sep 2020].

5 Kochhar R. Unemployment rose higher in three months of COVID-19 than it did in two years of the great recession. Available: https://www. pewresearch.org/fact-tank/2020/06/11/unemployment-rose-higherin-three-months-of-covid-19-than-it-did-in-two-years-of-the-greatrecession/ [Accessed 16 Sep 2020].

6 United States Department of Health and Human Services (US DHHS) Centers for Disease Control and Prevention (CDC). Coronavirus disease 2019 (COVID-19): older adults.

7 Ayalon L, Chasteen A, Diehl M. Aging in times of the COVID-19 pandemic: avoiding Ageism and fostering intergenerational solidarity. $J$ Gerontol B Psychol Sci Soc Sci 2020.

8 Romero Starke K, Petereit-Haack G, Schubert M, et al. The agerelated risk of severe outcomes due to covid-19 infection: a rapid review, meta-analysis, and meta-regression. Int J Environ Res Public Health 2020;17:5974-24.

9 Hawryluck L, Gold WL, Robinson S, et al. SARS control and psychological effects of quarantine, Toronto, Canada. Emerg Infect Dis 2004;10:1206-12.

10 Jeong H, Yim HW, Song Y-J, et al. Mental health status of people isolated due to middle East respiratory syndrome. Epidemiol Health 2016;38:e2016048.

11 Tull MT, Edmonds KA, Scamaldo KM, et al. Psychological outcomes associated with Stay-at-Home orders and the perceived impact of COVID-19 on daily life. Psychiatry Res 2020;289:113098.

12 Liu CH, Zhang E, Wong GTF, et al. Factors associated with depression, anxiety, and PTSD symptomatology during the COVID-19 pandemic: clinical implications for U.S. young adult mental health. Psychiatry Res 2020;290:113172.

13 Liu CH, Stevens C, Conrad RC, et al. Evidence for elevated psychiatric distress, poor sleep, and quality of life concerns during the COVID-19 pandemic among U.S. young adults with suspected and reported psychiatric diagnoses. Psychiatry Res 2020;292:113345.

14 Ettman CK, Abdalla SM, Cohen GH, et al. Prevalence of depression symptoms in US adults before and during the COVID-19 pandemic. JAMA Netw Open 2020;3:e2019686.

15 Czeisler Mark É, Lane RI, Petrosky E, et al. Mental health, substance use, and suicidal ideation during the COVID-19 pandemic United States, June 24-30, 2020. MMWR Morb Mortal Wkly Rep 2020;69:1049-57.

16 Shankar A, Hamer M, McMunn A, et al. Social isolation and Ioneliness: relationships with cognitive function during 4 years of follow-up in the English longitudinal study of ageing. Psychosom Med 2013;75:161-70.

17 Swift SL, Elfassy T, Bailey Z, et al. Association of negative financial shocks during the great recession with depressive symptoms and substance use in the USA: the cardia study. J Epidemiol Community Health 2020;74:jech-2020-213917.

18 Dong L, Freedman VA, Mendes de Leon CF. The association of comorbid depression and anxiety symptoms with disability onset in older adults. Psychosom Med 2020;82:158-64. 
19 Cacioppo JT, Hawkley LC, Thisted RA. Perceived social isolation makes me sad: 5-year cross-lagged analyses of loneliness and depressive symptomatology in the Chicago health, aging, and social relations study. Psychol Aging 2010;25:453-63.

20 Taylor HO, Taylor RJ, Nguyen AW, et al. Social isolation, depression, and psychological distress among older adults. J Aging Health 2018;30:229-46.

21 Shankar A, McMunn A, Banks J, et al. Loneliness, social isolation, and behavioral and biological health indicators in older adults. Health Psychol 2011;30:377-85.

22 Centers for Disease Control and Prevention (CDC). COVID-19 hospitalization and death by age hospitalization and death by age coronavirus disease 2019 (COVID-19) rate ratios compared to 18-29 year olds, 2020. Available: https://www.cdc.gov/coronavirus/2019ncov/covid-data/investigations-discovery/hospitalization-death-byage.html [Accessed 16 Sep 2020].

23 et alCreswell JW, Klassen AC, Plano V. Best practices for mixed methods research in the health sciences, 2011. Available: https:// obssr.od.nih.gov/wp-content/uploads/2016/02/Best_Practices_for_ Mixed_Methods_Research.pdf [Accessed 16 Sep 2020].

24 Heckathorn DD, Cameron CJ. Network sampling: from snowball and multiplicity to respondent-driven sampling. Annu Rev Sociol 2017:43:101-19.

25 Valerio MA, Rodriguez N, Winkler P, et al. Comparing two sampling methods to engage hard-to-reach communities in research priority setting. BMC Med Res Methodol 2016;16:1-11.

26 United States Department of Health and Human Services (US DHHS), Centers for Disease Control and Prevention (CDC) National Center for Health Statistics (NCHS). Bridged-race population estimates 1990-2018. Available: https://wonder.cdc.gov/bridgedrace-v2018.html [Accessed 16 Sep 2020].

27 U.S. Census Bureau. Educational attainment in the United States: 2018. current population survey, 2018 annual social and economic supplement, 2019. Available: https://www.census.gov/data/ tables/2018/demo/education-attainment/cps-detailed-tables.html [Accessed 16 Sep 2020].

28 Executive Office of the President, Office of Management and Budget (OMB). Standards for maintaining, collecting, and presenting federal data on race and ethnicity 2016;81.

29 Gilles I, Bangerter A, Clémence A, et al. Collective symbolic coping with disease threat and othering: a case study of avian influenza. $\mathrm{Br} \mathrm{J}$ Soc Psychol 2013;52:83-102.

30 Faulkner J, Schaller M, Park JH, et al. Evolved disease-avoidance mechanisms and contemporary xenophobic attitudes. Group Processes \& Intergroup Relations 2004;7:333-53.

31 Navarrete CD, Fessler DMT. Disease avoidance and ethnocentrism: the effects of disease vulnerability and disgust sensitivity on intergroup attitudes. Evol Hum Behav 2006;27:270-82.

32 et alWallace RB, Weir DR, Langa KM. Hrs / ahead documentation report. documentation of affective functioning measures in the health and retirement study, 2005. Available: hrsonline.isr.umich.edu/ sitedocs/userg/dr-009.pdf [Accessed 16 Sep 2020].

33 Lewinsohn PM, Seeley JR, Roberts RE, et al. Center for epidemiologic studies depression scale (CES-D) as a screening instrument for depression among community-residing older adults. Psychol Aging 1997;12:277-87.

34 Russell D. UCLA loneliness scale version 3 (instructions). J Pers Assess 1996;66:3-4.

35 Kobayashi LC, Steptoe A. Social isolation, loneliness, and health behaviors at older ages: longitudinal cohort study. Ann Behav Med 2018;52:582-93.
36 Lai J-S, Wagner LI, Jacobsen PB, et al. Self-reported cognitive concerns and abilities: two sides of one coin? Psychooncology 2014;23:1133-41.

37 Marshall C, Rossman G. Designing qualitative research. 6th edn. Newbury Park, CA: Sage Publications, 2016.

38 Lumley T. Survey: analysis of complex survey samples. 2020. R package version 4.0.

39 Valliant R. Comparing alternatives for estimation from nonprobability samples. J Surv Stat Methodol 2020;8:231-63.

40 U.S. Census Bureau, 2018 American Community Survey 1-Year Estimates. Total population in the United States, 2018. Available: https://data.census.gov/cedsci/map?q=Total Population in the United States\&g=0100000US.04000.001\&tid=ACSDP1Y2018. DP05\&vintage=2018\&layer=VT_2018_040_00_PP_ D1\&cid=DP05_0001E [Accessed 16 Sep 2020].

41 Buuren Svan, Groothuis-Oudshoorn K. mice: Multivariate Imputation by Chained Equations in R. J Stat Softw 2011;45:1-67.

42 Deville J-C, Särndal C-E. Calibration estimators in survey sampling. J Am Stat Assoc 1992;87:376-82.

43 Lumley T. Analysis of complex survey samples. J Stat Softw 2004;9:1-19.

44 Couper MP, Kalton G, Rao JN, eds. Complex surveys: a guide to analysis using $R$. Hoboken, New Jersey: John Wiley \& Sons, Inc, 2010.

45 Abrams LR, Mehta NK. Changes in depressive symptoms over age among older Americans: differences by gender, race/ethnicity, education, and birth cohort. SSM Popul Health 2019;7:100399.

46 Hawkley LC, Wroblewski K, Kaiser T. Supplemental material for are us. older adults getting Lonelier? age, period, and cohort differences. Psychol Aging 2019;34:1144-57.

47 Pearman A, Hughes ML, Smith EL, et al. Age differences in risk and resilience factors in COVID-19-Related stress. J Gerontol Ser B 2020;2019:2019-20.

48 Reynolds K, Pietrzak RH, El-Gabalawy R, et al. Prevalence of psychiatric disorders in U.S. older adults: findings from a nationally representative survey. World Psychiatry 2015;14:74-81.

49 Grenier S, Payette M-C, Gunther B, et al. Association of age and gender with anxiety disorders in older adults: a systematic review and meta-analysis. Int J Geriatr Psychiatry 2019;34:397-407.

50 Lawlor DA, Tilling K, Davey Smith G, et al. Triangulation in aetiological epidemiology. Int J Epidemiol 2016;45:1866-86.

51 Congressional Research Service. Domestic public health response to COVID-19 : current status, 2020. Available: https://crsreports. congress.gov/product/pdf/IN/IN11253 [Accessed 16 Sep 2020].

52 Bowleg L. The problem with the phrase women and minorities: intersectionality-an important theoretical framework for public health. Am J Public Health 2012;102:1267-73.

53 Pew Research Center. Internet/Broadband fact sheet, 2019. Available: https://www.pewresearch.org/internet/fact-sheet/internetbroadband/ [Accessed 1 Dec 2020].

54 America, inflamed. join Us for a special conversation about race. The New York Times. Available: https://www.nytimes.com/2020/06/ 01/us/george-floyd-ahmaud-arbery-race.html [Accessed $16 \mathrm{Sep}$ 2020].

55 Regnault A, Willgoss T, Barbic S, et al. Towards the use of mixed methods inquiry as best practice in health outcomes research. $J$ Patient Rep Outcomes 2017;2:2-5.

56 Tariq S, Woodman J. Using mixed methods in health research. JRSM Short Rep 2013;4:204253331347919. 